\title{
Artikel
}

\section{De weg naar de erkenning van de Nederlandse Gebarentaal (NGT)}

\section{Wanneer, hoe en waarom zijn we begonnen met te vragen om erkenning van NGT?}

\section{R. Cokart en T. Schermer*}

Op 13 oktober 2020 werd er een feestelijke historische mijlpaal bereikt voor de Nederlandse dovengemeenschap. Op die dag aanvaardde de Eerste Kamer unaniem het initiatiefwetsvoorstel voor de wettelijke erkenning van de Nederlandse Gebarentaal (NGT). De kern van de wet is de wettelijke erkenning van NGT als een officiële taal in Nederland, naast het Nederlands en het Fries. Deze wettelijke erkenning van de eigen moedertaal is voor de dovengemeenschap het sluitstuk van haar jarenlange strijd voor erkenning voor de eigen taal, cultuur en identiteit. In dit artikel zullen vooral de lobby en de totstandkoming van de erkenning van NGT worden beschreven. Eerst komt de ontwikkeling van gebarentaal in de voorgaande eeuw(en) aan bod.

\section{Voorgeschiedenis}

De Nederlandse Gebarentaal, die al eeuwen in Nederland gebruikt wordt, is de moedertaal van de meeste doven in Nederland. De eerste school voor doven in Nederland werd in 1790 in Groningen opgericht door

R. (Richard) Cokart is een native gebarentalige en linguïst en werkt als senior onderzoeker bij het Nederlands Gebarencentrum. T. (Trude) Schermer is linguïst en voormalig directeur van het Nederlands Gebarencentrum en is sinds de jaren tachtig betrokken bij onderzoek naar NGT en bij het proces van erkenning van NGT. Dit artikel is gebaseerd op een artikelenreeks die in 2020 in Woord en Gebaar (het enige onafhankelijke, landelijke dovenblad van Nederland) is verschenen, geschreven door Richard Cokart, Daniël Scheper, Trude Schermer, Corrie Tijsseling en Iris Wijnen.
Henri Daniël Guyot. In die tijd werd in heel Europa gebruik gemaakt van de ideeën van de Franse abt De l'Épée, die aantoonde dat dove mensen heel goed onderwijs konden krijgen door gebruik te maken van gebaren. Het Instituut in Groningen werd een broedplaats van gebaren, dove leerlingen ontwikkelden zelf gebaren met elkaar, dove kinderen van dove ouders brachten de gebaren in van hun families, er waren dove leerkrachten en zo ontstonden wat we nu noemen de Groningse gebaren.

Op dezelfde manier zijn gebaren ontstaan in de andere regio's waar scholen voor doven opgericht werden: in Sint-Michielsgestel in 1840, in Rotterdam in 1853, in Leiden (later Voorburg) in 1888 en in Amsterdam in 1911. Het gebruik van gebaren in dovenonderwijs werd echter in 1880 tijdens een congres van leerkrachten in het dovenonderwijs in Milaan verboden. Er was toen sprake van een 'methodenstrijd', waarbij de vraag of de leerlingen moesten spreken of mochten gebaren centraal stond. De deelnemers verklaarden dat de spreekmethode (oralisme) superieur was an de gebarenmethode en namen een resolutie aan die het gebruik van gebarentaal op school verbood. De resolutie van Milaan had enorme gevolgen voor het onderwijs aan dove kinderen. ${ }^{1}$ Vanaf 1910 tot 1980 zouden gebaren strikt verbannen blijven in het onderwijs aan dove kinderen in Nederland. Dit had grote gevolgen voor de taal- en cognitieve ontwikkeling van dove kinderen. Deze periode wordt in de dovengemeenschap weleens de 'dark ages' van dove

1. C. Tijsseling, School, waar? Een onderzoek naar de betekenis van het Nederlandse dovenonderwijs voor de Nederlandse dovengemeenschap, 1790-1990, PhD thesis, Universiteit Utrecht 2014. 

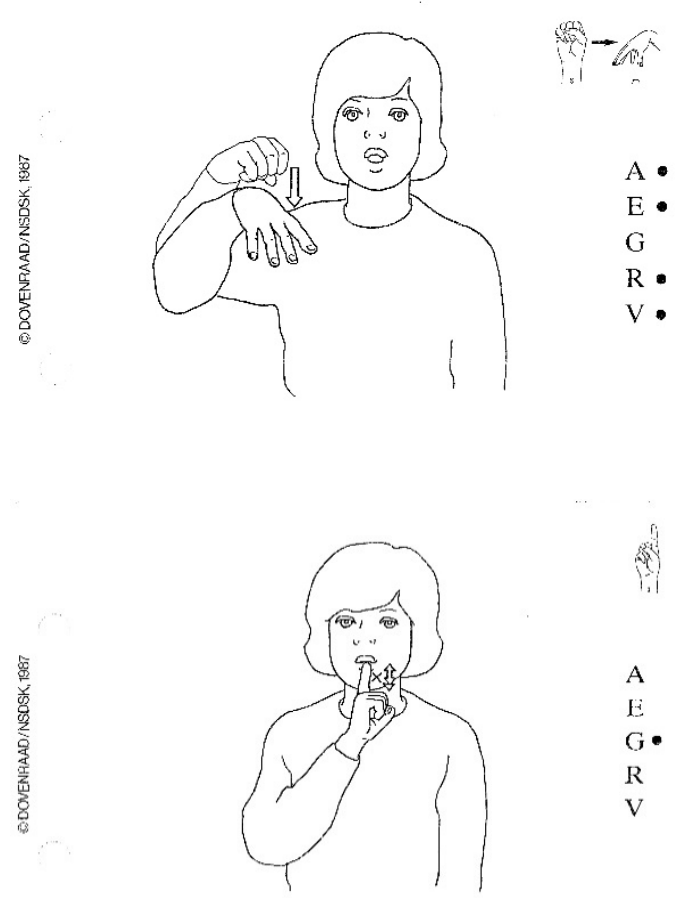

mensen genoemd. Onderling bleven dove mensen echter gewoon gebaren gebruiken, ondanks het verbod om gebarentaal te gebruiken op school. Dit heeft tot gevolg gehad dat er in Nederland een gebarentaal bleef bestaan die zich ook verder ontwikkelde. Er waren verschillen tussen de regio's (regionale varianten) en tussen verschillende leeftijden (oudere en jongere dove leerlingen van de scholen) en ook tussen jongens en meisjes (met name in Sint-Michielsgestel).

We hebben het sinds begin jaren tachtig over dé Nederlandse Gebarentaal en daarmee wordt bedoeld de gebarentaal van dove mensen in Nederland met alle regionale verschillen. ${ }^{2}$ Figuren 1 en 2 illustreren de verschillen in regionale varianten voor het begrip LAMP.

De vraag of gebarentalen natuurlijke talen zijn werd pas in de jaren 1960 beantwoord: een gebaar kan op dezelfde manier als een gesproken woord in kleinere talige elementen opgedeeld worden. De Amerikaanse linguïst William Stokoe was de grondlegger van het taalkundige onderzoek naar gebarentalen. Hij toonde aan dat ze linguistisch geanalyseerd konden worden en dat was het begin van onderzoek wereldwijd naar de gelijkenissen en verschillen tussen gebarentalen en gesproken talen. ${ }^{3} \mathrm{De}$

2. In 1953 is in Nederland al onderzoek gedaan naar de gebaren van jonge dove kinderen (B. Tervoort, Structurele analyse van visueel taalgebruik binnen een groep dove kinderen, PhD thesis, Universiteit van Amsterdam 1953). In 1981 werd voor het eerst onderzoek gedaan naar de taal van volwassen doven en werd aangetoond dat deze taal een volwaardige taal is met een eigen lexicon en eigen grammatica (T. Schermer, In search of a language. Influences from spoken Dutch on Sign Language of the Netherlands. PhD thesis, Universiteit van Amsterdam 1990. T. Schermer, C. Fortgens, R. Harder \& E. de Nobel, De Nederlandse Gebarentaal, Twello: Van Tricht Uitgeverij 1991).

3. W. Stokoe, Sign language structure: An outline of the visual communication systems of the American Deaf, Studies in Linguistics, Occasional wetenschappelijke erkenning van gebarentalen als echte taal, gelijkwaardig aan gesproken talen, was een belangrijke ontwikkeling in het proces van de emancipatie van dove mensen en sinds 1880 een eerste stap in de maatschappelijke erkenning van gebarentalen.

\section{Achtergrond van de strijd naar erkenning}

Het proces om de Nederlandse Gebarentaal erkend te krijgen, begon in de late jaren 1970. In die tijd waren doven een achtergestelde en veelal laagopgeleide minderheid, wat een directe gevolg was van taaldeprivatie in het dovenonderwijs. Het gebruik van gebaren was in het onderwijs aan dove kinderen uit den boze en het maken van gebaren werd niet als een volwaardige taal beschouwd. De wens van doven om erkend te worden als een minderheidsgroep kwam tot uiting in het thema van het eerste Nationaal Dovencongres dat in 1979 werd georganiseerd door de Nederlandse Dovenraad: 'Plaatsmaken voor de Dove medeburger'. ${ }^{4}$ Dit Dovencongres kan worden gezien als het startpunt van de emancipatie van doven in Nederland. In 1981 sloegen dove gemeenschapsleiders, de organisatie van ouders van dove kinderen (FODOK), de Nederlandse Stichting voor het Dove en Slechthorende Kind (NSDSK) en de Universiteit van Amsterdam de handen ineen en publiceerden een

Papers, 8, Buffalo, N.Y.: University of Buffalo Department of Anthropology and Linguistics 1960

4. Dovenschap (voorheen Dovenraad) is de landelijke belangenvereniging voor doven. 
boek over de positie van doven. ${ }^{5}$ Bijna veertig jaar later is de maatschappelijke positie van doven aanzienlijk verbeterd. Doven hebben allerlei verschillende opleidingen en beroepen en er is een Wet Centralisering Tolkvoorzieningen (mei 2019) waarin het recht op de inzet van tolken in de privésfeer, werksfeer en onderwijssfeer is vastgelegd. ${ }^{6}$ Dat is ooit wel eens anders geweest. In 1983 begon de Dovenraad te lobbyen voor tolkvoorzieningen voor dove mensen, wat resulteerde in de tolkvoorziening voor doven die in 1988 werd geïntroduceerd. ${ }^{7}$

Naarmate de dovengemeenschap sinds eind jaren zeventig meer zelfbewust werd en bewust van het feit dat hun taal ook een echte taal was, groeide ook het verlangen naar wettelijke erkenning van de NGT. Ook in het buitenland, met name in Denemarken en $Z$ weden, zagen de Nederlandse dove mensen dat hun eigen gebarentalen veel meer erkend waren dan in Nederland het geval was. De kiem voor de roep om erkenning van de eigen gebarentaal in verschillende landen in Europa en daarbuiten is gelegd op 17 juni 1988 toen er een resolutie werd aangenomen in het Europees Parlement waarin alle aangesloten leden werden opgeroepen hun gebarentaal te erkennen. ${ }^{8}$

In maart 1996 werd een Commissie NGT ingesteld door het Ministerie van Onderwijs, Cultuur en Wetenschappen (OCW), en het Ministerie van Volksgezondheid, Welzijn en Sport (VWS). De taakstelling van deze commissie was: 'voorstellen te doen voor de wijze waarop optimaal uitvoering gegeven kan worden aan de officiële erkenning van de Nederlandse Gebarentaal'. De opdracht was dus niet zozeer om te adviseren over de vraag óf de NGT zou moeten worden erkend, maar om te adviseren over de manier waarop.

Deze commissie maakte een rapport over wat NGT is, en waarom deze taal erkend zou moeten worden. Ook bevatte het rapport 64 aanbevelingen over de manier hoe NGT wettelijk erkend kon worden. Bovendien lichtte het rapport toe wat erkenning van NGT zou betekenen voor het persoonlijk leven van doven, en wat het zou betekenen voor wet- en regelgeving binnen het sociale en juridische domein en met betrekking tot onderwijs en (psychische) gezondheid. Het rapport verscheen in 1997, met de titel Meer dan een gebaar. ${ }^{9}$

In navolging hiervan ondertekenden de dovenscholen een convenant met de overheid waarin vastgelegd werd dat alle dovenscholen tweetalig onderwijs zouden

5. Nederlandse Dovenraad, Wie niet horen kan moet maar zien, Bussum Uitgeverij Coutinho 1981.

6. Wet centraliseren tolvoorzieningen auditief beperkten, luisterlijnen en vertrouwenswerk jeugd, Stb. 2019, 221 en 222

7. Ministerie van Sociale Zaken en Werkgelegenheid, Stcrt. 1995, 123, p. 12.

8. European Parliament, Committee on Culture and Education, 1988. Resolution on sign languages for the deaf. OJ C 187, 18.7.1988, p. 236.

9. A. Baker, H. Knoors, T. van der Lem, M. Schadee \& J. Wesemann, Meer dan een gebaar, rapport van de Commissie Nederlandse Gebarentaal, 1997. bieden, in de NGT en het Nederlands. Ook werd vastgelegd dat er een NGT-curriculum voor het speciaal onderwijs ontwikkeld zou worden (Taal op Maat), en dat het basislexicon van de NGT ten bate van het onderwijs gestandaardiseerd werd, een eis van de overheid om tot erkenning van de NGT te komen. ${ }^{10} \mathrm{Er}$ gebeurde nog meer in dit tijdsbestek: in 1996 werd het Nederlands Gebarencentrum opgericht en in 1997 begon de nieuwe hbo-opleiding voor tolk/docent NGT aan de HU.

\section{De rol van belangenorganisaties en de Commissie Erkenning NGT}

In 2001 hield de dovengemeenschap de eerste protestmars voor de wettelijke erkenning van NGT. Dit was een reactie op het besluit van de Commissie NGT om zichzelf op te heffen omdat er geen voortgang geboekt werd sinds $1997 .{ }^{11}$ Twee jaar later, in 2003, nam Dovenschap samen met het Nederlands Gebarencentrum het initiatief om een nieuwe commissie in te stellen. ${ }^{12}$ Deze commissie nam het initiatief tot verschillende ontmoetingen tussen belanghebbenden en de Ministeries van OCW en VWS, met als doel om de overheid te overtuigen van het nut van de wettelijke erkenning van NGT en om de ministeries te herinneren aan de belofte dat na standaardisatie van het lexicon van NGT wettelijke erkenning zou volgen. In 2004 vond een ontmoeting plaats tussen leden van de nieuwe Commissie Erkenning NGT en de Staatssecretaris van VWS. Voorafgaand had de commissie een document opgesteld waarin beargumenteerd werd dat de NGT weliswaar steeds meer zichtbaar werd, maar dat integratie van dove mensen in de Nederlandse samenleving niet vanzelfsprekend was. ${ }^{13}$ Opnieuw werd gepleit voor wettelijke erkenning van de NGT, om de natuurlijke taal van dove mensen te beschermen zodat zij gelijkwaardig zijn aan horenden en om te voorkomen dat NGT ooit weer onderdrukt wordt door horende onderwijzers in het onderwijs aan doven. In de zomer van 2004 hield de dovengemeenschap opnieuw een protestmars. ${ }^{14}$

Kort na deze mars schreef de Staatssecretaris van VWS een reactie ${ }^{15}$ op het rapport over de status van gebarentalen in Europa, ${ }^{16}$ dat in 2003 verschenen was bij de

10. T. Schermer (2003), 'Standaardisatie, en nu?', Van Horen Zeggen 44 (1), 15-19.

11. A. de Ronde (2001), 'Nederlandse gebarentaal vóór 2002 erkend', Woord \& Gebaar 21 (1), 8-9

12. Commissie Erkenning NGT, met daarin: A. Baker (UvA), H. Bakker (KEGG), H. Bennis (Meertens Instituut), B. Elferink (Dovenschap) en T. Schermer (Nederlands Gebarencentrum).

13. T. Schermer, J. Wesemann \& B. Elferink, Notitie Nederlandse Gebarentaal, ongepubliceerd manuscript, Nederlands Gebarencentrum 2004

14. D. Schoevaart (2004), 'De mars', Woord \& Gebaar 24 (6), 6-9.

15. Kamerstukken I/ 2003/04, 29200-XVI, nr. 249.

16. N. Timmermans, A Comparative Analysis of the Status of Sign Languages in Europe, Straatsburg: Council of Europe 2003. 
Raad van Europa. De Ministeries van VWS en OCW stelden dat de activiteiten van de Raad van Europa alleen konden gaan over de instrumentele rechten van gebarentaligen en niet over de wettelijke status van de taal zelf. Zij bedoelden: de Raad van Europa moest alleen kijken of doven in een gebarentaal mogen en kunnen communiceren. De Raad zou zich niet bezig moeten houden met wettelijke erkenning van talen. Bovendien vonden de Ministeries van VWS en OCW dat er eerst goed gekeken moest worden naar de behoeften van gebarentaligen, voordat er een keuze werd gemaakt voor een bepaald wettelijk instrument. De conclusie van de Staatssecretaris van VWS was dat erkenning van de NGT geen toegevoegde waarde had en dat de overheid de problemen van dove mensen beter op een praktische manier kon oplossen.

De Commissie Erkenning NGT heeft in 2010 geprobeerd om de Nederlandse Gebarentaal in de Grondwet erkend te krijgen. Maar na het negatieve advies van de Raad van State is deze weg niet verder ingeslagen. Omdat het Nederlands niet in de Grondwet staat en ook niet zou hoeven te staan volgens deze commissie, kan ook de Nederlandse Gebarentaal niet in de Grondwet worden opgenomen. Als gevolg van deze houding van de overheid stopte de Commissie Erkenning NGT in 2010 met al haar activiteiten. De commissie moest zich een weg banen door de vele verschillende lagen van verschillende departementen, waardoor de activiteiten steeds meer onduidelijk werden en steeds minder effect hadden. De reden was dat geen enkel ministerie de verantwoordelijkheid wilde nemen voor enige actie op het gebied van wettelijke erkenning van de NGT.

\section{De positie van het Nederlands en het Fries}

Omdat de positie van het Nederlands en het Fries belangrijk zijn in verband met de mogelijkheden om de Nederlandse Gebarentaal wettelijk te erkennen, gaan we hier apart op in. Voor de meeste Nederlanders was het tot 1996 eigenlijk niet zo bekend dat het Nederlands niet in onze Grondwet verankerd is als de taal van ons land. In dat jaar werd een motie ingediend door het Gereformeerd Politiek Verbond (GPV) en het Christen-Democratisch Appèl (CDA) om het Nederlands in de Grondwet op te nemen. Op die manier zou het Nederlands beschermd worden tegen de invloed van de globalisatie en het toenemend gebruik van het Engels in bijvoorbeeld het onderwijs. ${ }^{17}$ De overige politieke partijen vonden het niet nodig om het Nederlands in de Grondwet op te nemen. Bovendien is het Nederlands beschermd als de nationale taal van Nederland binnen de Europese

17. P. van den Eijnden (2011), 'De Nederlandse taal in de Grondwet', Tijdschrift voor Constitutioneel Recht, juli 2011, 315-324.
Unie, waar de nationale talen van de lidstaten erkend zijn als taal. ${ }^{18}$

Het Fries is een verzameling van Friese talen die verwant zijn aan West-Germaanse talen en die al eeuwenlang door de Friezen gesproken worden. Het Fries heeft een speciale status in Nederland. In 1938 werd de Friese Academie (Fryske Akademy) opgericht ter bevordering en uitvoering van wetenschappelijk en toegepast onderzoek naar de Friese taal. Het Fries is in 1955 erkend als officiële taal naast het Nederlands in het lager onderwijs en sinds 1956 is het Fries ook toegestaan in de rechtspraak in Friesland. ${ }^{19}$ In 1980 werd het Fries verplicht op basisscholen en in 1993 ook in de eerste jaren van het middelbaar onderwijs. In 1997 werd het Fries officieel de taal in het openbaar bestuur en rechtspraak in Friesland.$^{20}$ In 2013 werd de positie van het Fries nog versterkt door de invoering van een taalwet waarin het Fries én het Nederlands de officiële talen zijn in de provincie Friesland en waarin bepaald is dat de Friezen het recht hebben om hun taal te gebruiken in rechtbanken en in het contact met openbaar bestuurlijke instanties in Friesland. ${ }^{21}$ Daarnaast is er een orgaan voor de Friese taal ingesteld dat het Fries moet beschermen en het gebruik ervan bevorderen. Deze taalwet stond model voor het initiatiefwetsontwerp Erkenning Nederlandse Gebarentaal dat in 2016 is angeboden aan de Tweede Kamer, en is voorgelegd aan de Raad van State.

\section{De aanloop naar wettelijke erkenning voor NGT en het wetsontwerp}

In 2013 heeft Dovenschap een nieuw bestuur geïnstalleerd en een van de doelen was om de wettelijke erkenning van NGT na te streven. Toen politicus Roelof van Laar in 2014 Tweede Kamerlid werd voor de PvdA, kondigde hij aan bereid te zijn een wetsvoorstel in te dienen voor de wettelijke erkenning van NGT. Het bestuur van Dovenschap is met Van Laar in gesprek gegaan over de inhoud van het voorstel. In het eerste ontwerp werd NGT vooral een instrumentele waarde toegekend, waarbij doven werden gezien als mensen die 'afhankelijk zijn' van NGT. Daarnaast bevatte het ontwerp een scala aan onderwerpen die verband houden met de deelname van doven aan de samenleving, zoals telecommunicatie en hulpdiensten. Het ontwerpwetsvoorstel was bedoeld om alle problemen van doven op te lossen. Dovenschap wilde echter afstand nemen van het oude en ongepaste 'defecte'-raamwerk, dat doven bestempelt als mensen met defecte oren en verstoken

18. Kamerstukken / 1995/96, 24431, A.

19. B.D. van der Velden, Waar gaan we heen met het Fries? Het gebruik van de Friese taal in het juridische en in het bestuurlijke verkeer in de laatste twee eeuwen, PhD thesis, Universiteit van Amsterdam 2004.

20. Kamerstukken // 2011/12, 33335, nr. 3, p. 4.

21. Kamerstukken / 2012/13, 33335, A. 
van 'taal'. In plaats daarvan wilde Dovenschap doven profileren als een taalkundige en culturele minderheid, die alleen gehandicapt is als ze geen toegang hebben tot communicatie en informatie: doof zijn is zowel een handicap als een taalidentiteit. ${ }^{22}$

Het feit dat er een klein aantal gebarentaligen in een land is, wordt vaak gebruikt als argument voor het inhouden of beperken van taalrechten. ${ }^{23}$ Hoewel dit in Nederland nooit het geval was, besloot Dovenschap om het aantal gebarentaligen te bepalen en dit te vergelijken met het aantal gebruikers van andere minderheidstalen en regionale talen. Op basis van een recent onderzoek zijn er in Nederland ongeveer 11.900 tot 20.400 doven die in de eerste drie levensjaren doof zijn geboren of doof zijn geworden. ${ }^{24}$ Rekening houdend met horende ouders en broers en zussen van dove mensen, die meestal NGT leren tot een bepaald niveau, samen met horende kinderen van dove ouders die vaak native gebarentaligen zijn en tolken NGT, zijn er naar schatting 60.000 mensen die NGT gebruiken, op verschillende taalvaardigheidsniveaus.

Op 3 oktober 2016 werd samen met de ChristenUnie een wetsvoorstel ingediend dat tot stand was gekomen in nauwe samenwerking met Dovenschap. De ChristenUnie was erbij betrokken omdat deze politieke partij al een aantal jaren pleitte voor erkenning van NGT. ${ }^{25}$ Van Laar had op de meeste punten toegegeven aan Dovenschap. Het uiteindelijke wetsvoorstel - en de bijgevoegde memorie van toelichting - richtte zich op de wettelijke erkenning van NGT en het bevorderen van NGT. Naast de juridische erkenning van de NGT als officiële taal beoogt het wetsvoorstel onder meer de volgende zaken te regelen: bevordering van het gebruik van NGT door de rijksoverheid, mede door een jaarlijkse rapportage over de staat van NGT, en de instelling van een adviesorgaan dat de Minister van Binnenlandse Zaken en Koninkrijksrelaties adviseert over het bevorderen van het gebruik van NGT.

\section{Inhoud van het wetsvoorstel}

Het voorstel houdt in dat alle openbare overheidscommunicatie, zoals openbare toespraken van parlementsleden, toegankelijk in NGT moeten zijn. De overheid heeft de taak personen die doof zijn te informeren over voor hen belangrijke zaken op een manier die voor hen

22. M. De Meulder, The power of language policy. The legal recognition of sign languages and the aspirations of deaf communities, PhD thesis, University of Jyväskylä 2016

23. S. Wilcox, V. Krausneker \& D. Armstrong, 'Language policies and the Deaf community', in: B. Spolsky (red.) Cambridge Handbook of Language Policy, Cambridge: Cambridge University Press 2012, p. 374-395.

24. P. Prawiro-Atmodjo, M. Langendoen \& C. Tijsseling, Literatuurstudie naar de leefsituatie van vroegdove volwassenen, Sint-Michielsgestel: Koninklijke Kentalis 2016.

25. ChristenUnie, Positie Doven Versterken, Nederlandse Gebarentaal Erkennen!, Den Haag: ChristenUnie 2010 te begrijpen is. Ondertiteling of tekst aanbieden is daarbij vaak niet voldoende, omdat steeds weer uit onderzoek blijkt dat gesproken talen niet volledig toegankelijk zijn en daardoor geschreven talen (die een uitdrukking zijn van gesproken talen) onvoldoende begrepen worden. De Minister van Binnenlandse Zaken en Koninkrijksrelaties krijgt de taak om een beleid te voeren dat erop is gericht te bevorderen dat er vaker gebruik gemaakt wordt van NGT bij openbare toespraken van het kabinet, in het bestuurlijk verkeer en in het rechtsverkeer. Het doel is om de communicatie van de overheid toegankelijker te maken voor personen die doof zijn enerzijds, en personen die doof zijn en hun communicatiebehoeften zichtbaarder te maken voor het brede publiek anderzijds. Daarnaast moet de gesproken berichtgeving in nationale crisis- of noodsituaties zo veel mogelijk vertaald worden naar NGT. Gebarentaligen krijgen het recht om ter uitvoering van een wettelijk voorschrift een mondelinge eed, belofte of bevestiging te afleggen in NGT die met de woorden van die eed, belofte of bevestiging corresponderen.

Ten slotte wordt voorgesteld de instelling van een adviesorgaan voor de bescherming en promotie van NGT, en wordt daarbij het Nederlands Gebarencentrum, dat reeds functioneert als onafhankelijk landelijk expertisecentrum op het terrein van Nederlandse Gebarentaal en Nederlands met Gebaren ( $\mathrm{NmG})$, genoemd als het aangewezen instituut voor het adviesorgaan. ${ }^{26}$ Deze functie is vergelijkbaar met de functie van het adviesorgaan voor de Friese taal (DINGtiid). Dit laatste ziet toe op de status en het gebruik van het Fries in de provincie.

Zoals eerder vermeld heeft Dovenschap de Friese taalwet als model gebruikt voor het wetsvoorstel voor NGT. Er zijn twee overeenkomsten tussen het NGTwetsvoorstel en de Friese taalwet: het gebruik van de minderheidstaal in de communicatie met de overheid (direct of via tolken) en de oprichting van een adviesorgaan voor de bescherming en bevordering van de Friese taal. Echter, in het voorstel voor de wettelijke erkenning van NGT wordt alleen een eenrichtingscommunicatie van de overheid naar gebarentaligen benoemd en het beperkt zich tot officiële publiekscommunicatie zoals websites en toespraken van overheidsfunctionarissen. Terwijl de Friese taalwet alle overheidscommunicatie behelst en het recht van de Friese burger om Fries te gebruiken bij communicatie met overheidsinstanties vermeldt. Ook staat de Friese wet het gebruik van Fries toe in het juridische domein, zoals bij rechtbanken, hetgeen niet wordt genoemd in het wetsvoorstel voor de wettelijke erkenning van NGT.

26. Kamerstukken // 2016/17, 34562, nr. 2 


\section{Parlementaire behandeling}

Nadat het wetsvoorstel naar het parlement was gestuurd, is het vervolgens naar de Raad van State gestuurd, die de Minister van Binnenlandse Zaken adviseert. In maart 2017 vonden verkiezingen plaats voor een nieuw parlement en kwam het bovengenoemde proces tot stilstand. De PvdA leed een historisch verlies, waardoor Van Laar geen lid meer was van de Tweede Kamer. Dovenschap nam contact op met de ChristenUnie (CU) om hen te vragen het proces rond de erkenning van NGT nieuw leven in te blazen. Dovenschap startte ook een petitie, ondertekend door 15.737 mensen en lanceerde een campagne \#NGTnu om het bewustzijn te vergroten over het belang van de wettelijke erkenning van NGT. De CU reageerde positief op deze acties en stelde dat er belangrijke stappen moesten worden gezet. In april 2018 hebben CU en Dovenschap een overleg gevoerd over het proces en werd afgesproken dat CU en PvdA het wetsvoorstel in de Tweede Kamer ter bespreking zouden inbrengen.

Een belangrijk instrument dat naar verwachting de bereidheid van Nederlandse politici om het wetsvoorstel voor de erkenning van NGT te accepteren zou vergroten, is het VN-Verdrag inzake de rechten van personen met een handicap (VN-verdrag Handicap), dat sinds 14 juli 2016 in Nederland van kracht is. Tijdens het ratificatieproces heeft Dovenschap er vaak op gewezen dat het VN-verdrag Handicap een aantal clausules en richtlijnen bevat met betrekking tot de erkenning van nationale gebarentalen. Tijdens de $19 \mathrm{e}$ sessie van het VN-Comité voor de Rechten van Personen met een Handicap in Genève in april 2018, bevestigden commissieleden aan Dovenschap dat de erkenning van een gebarentaal als fundamenteel wordt beschouwd voor de implementatie van het VN-verdrag Handicap.

\section{Wijzigingen in het wetsvoorstel}

Het wetsvoorstel is in de afgelopen drie jaar voor advies langs de Raad van State geweest en vervolgens aangepast. ${ }^{27}$ Inmiddels was ook D66 aangeschoven als partij en is dit initiatiefwetsvoorstel ingediend op 27 september 2019 bij de agendacommissie voor de Tweede Kamer. $\mathrm{Na}$ een schriftelijke vragenronde in januari 2020, vond op 1 september 2020 het debat over het wetsvoorstel plaats in de Tweede Kamer. De bijdragen van PvdA, D66, CU, CDA, SP, SGP en VVD waren helder: de wettelijke erkenning van NGT is noodzakelijk en de initiatiefwet verdient ondersteuning. Complimenten waren er voor de initiatiefnemers en de volharding van de dovengemeenschap. De vragen over met name de implementatie en de gevolgen in de praktijk werden in tweede termijn beantwoord op 8 september 2020, waarbij ook een aantal moties is ingediend naar aanleiding van in de memorie van toelichting vermelde knelpunten. ${ }^{28}$

Tijdens het tweede debat werden er in totaal vier moties ingediend. De eerste motie, over de mogelijkheid om de onderwijsvoorzieningen voor dove mensen ouder dan 30 jaar uit te breiden, werd aangehouden. ${ }^{29}$ Voorheen werd de subsidie voor onderwijsvoorzieningen voor personen met een handicap, zoals de inzet van een tolk NGT, alleen toegekend aan personen jonger dan 30 jaar. Op 30 oktober 2020 schreef de Minister van OCW in een brief dat zij voornemens was om artikel 19a van de WOOS (Wet Overige OCW-subsidies) zo aan te passen dat ook studenten ouder dan 30 jaar die bekostigd voltijdsonderwijs volgen in het vavo, mbo en het ho in aanmerking kunnen komen voor ondersteuning met onderwijsvoorzieningen door het UWV.$^{30}$ De tweede motie, die direct werd aangenomen, bevatte het verzoek aan de regering om, indien het wetsvoorstel in beide Kamers zou zijn aangenomen, de gemeenschap van doven en slechthorenden actief te informeren over verankering van dit wetsvoorstel in beleid en wetgeving. ${ }^{31}$

De derde motie verzocht het presidium, samen met de NPO, afspraken te maken over de vertaling in de Nederlandse Gebarentaal van ten minste het wekelijkse vragenuur, de Algemene Politieke Beschouwingen en het slotdebat voor de Tweede Kamerverkiezingen. ${ }^{32}$ De derde motie werd ingetrokken nadat het presidium toezegde dat de Algemene Politieke Beschouwingen vanaf 2020 voorzien zou zijn van tolken NGT. Daarnaast zegde de minister van Binnenlandse Zaken en Koninkrijksrelaties toe om samen met de minister voor Basis- en Voortgezet Onderwijs en Media in gesprek te gaan met de NPO over de mogelijkheid om de verkiezingsdebatten te voorzien van een tolk NGT. Verder schreef de minister dat op 1 november 2020 de wijziging van de Mediawet 2008 inzake het aanbieden van audiovisuele mediadiensten in een veranderende marktsituatie in werking was getreden. ${ }^{33}$ Deze wet regelt dat publieke en commerciële omroepen ervoor moeten zorgen dat hun media-aanbod in toenemende mate toegankelijk wordt gemaakt voor mensen met een auditieve of visuele beperking.

De laatste motie verzocht de regering om gebarentaligen in sociale werkplaatsen recht te geven op een tolk vanuit de bestaande tolkvoorziening. ${ }^{34}$ Voor dove werkenden is het mogelijk om gebruik te maken van een tolk voor het vertalen van gesproken taal naar NGT via het UWV dat maximaal $15 \%$ van de arbeidstijd aan tolkuren vergoedt. Dat was niet van toepassing op gebarentaligen in sociale

\footnotetext{
Kamerstukken // 2019/20, 34562, nr. 7.

Kamerstukken // 2019/20, 34562, nr. 12

Kamerstukken I/ 2020/21, 34562, nr. 18

Kamerstukken I/ 2019/20, 34562, nr. 13.

Kamerstukken I/ 2019/20, 34562, nr. 14

Kamerstukken I/ 2020/21, 34562, nr. 19.

Kamerstukken // 2019/20, 34562, nr. 15
} 
werkplaatsen. $\mathrm{Nu}$ zijn deze werknemers sterk afhankelijk van het beleid van de gemeente en het sociale werkbedrijf dat de Wet sociale werkvoorziening (Wsw) namens deze gemeente lokaal of regionaal uitvoert. In een brief van 11 december 2020 schreef de Minister van Sociale Zaken en Werkgelegenheid dat hij niet voornemens is om het huidige beleid aan te passen aangezien hij geen concrete signalen ontvangen heeft dat sociale werkbedrijven hun gebarentalige werknemers een tolk ontzeggen. ${ }^{35}$

\section{Erkenning}

Op 22 september 2020 heeft de Tweede Kamer unaniem het wetsvoorstel voor erkenning van de Nederlandse Gebarentaal aangenomen. Vervolgens heeft de Eerste Kamer op 13 oktober 2020 het wetsvoorstel ook met algemene stemmen aanvaard.

\section{Ten slotte}

De wettelijke erkenning van NGT heeft een grote emotionele en psychologische impact op zowel oudere gebarentaligen, voor wie deze taal ooit verboden was, als op jonge gebarentaligen, omdat zo erkend wordt dat ook voor hen NGT ertoe doet. De wettelijke erkenning van de Nederlandse Gebarentaal draagt bij aan de bekendheid en het serieus nemen ervan. Dit vergemakkelijkt ook de inzet van tolken NGT en er zal meer vraag komen naar vertalingen van informatie op websites in NGT. Daarnaast gaat het ook over de waardigheid en identiteit van de doven, de erkenning dat NGT een volwaardige taal is. Voor de dovengemeenschap is NGT hun moedertaal. Met deze wettelijke erkenning zal in de toekomst NGT steeds meer geïmplementeerd worden in de Nederlandse samenleving. 